\title{
Optimisation of Off-Soil Tomato Fertilization and Substrate Recipes
}

\author{
Edouard Tabet ${ }^{1,2}$, Paul Sleiman ${ }^{2}$, Chadi Hosri², Souzi Rouphael ${ }^{2} \&$ Lina Farah $^{1}$ \\ ${ }^{1}$ CRFA: Centre de Recherche et Formation Agricole, Lebanese University, Ghazir, Lebanon \\ ${ }^{2}$ Faculty of Agriculture and Veterinary Medicine, Lebanese University, Beirut, Lebanon \\ Correspondence: Lina Farah, CRFA: Centre de Recherche et Formation Agricole, Lebanese University, Ghazir, \\ Lebanon. Tel: 9613-761-116. E-mail: lina.f.azar@gmail.com
}

Received: March 9, 2020 Accepted: March 27, 2020 Online Published: May 25, 2020

\begin{abstract}
Substrate and fertilizers recipes and their balances are two factors affecting the growth of hydroponic crops. However, the responses of crop cultivars to different substrate and fertilizer are less clear. This study was aimed at assessing the different responses of tomato (Solanum Lycopersicum L.) cultivars to the different substrate and fertilizer supply. The study was carried out at the Centre de Recherche et de Formation Agricole (CRFA) of the Lebanese University to test three types of substrates; S1 (100\% coconut fiber), S2 (50\% coconut fiber and 50\% grape marc) and S3 (25\% coconut fiber and 75\% grape marc). As well as three fertilization recipes; F1 (ARTC), F2 (University of Arizona) and F3 (Farmer) were applied in order to be able to recommend the best substrates and fertilizers adapted to the conditions of cultivation off-soil. The production cycle was divided into three phases; phase1 (0-6 weeks), phase2 (6-12 weeks) and phase3 ( $>12$ weeks). Various parameters were measured throughout the cycle; stem length, number and distance between nodes, number and distance between flower buds, and fruit yield. Results for stem length and number of nodes showed good interaction in favor of F2-S1 throughout the cycle. As far as the distance between nodes is concerned, F1 is the best despite the fact that F2 is more economical and S1 showed a superiority. The number of flower buds is positively affected by F1 and F2 and S1 and S3. As far as the distance between floral buds is concerned, F1 and F2 are the best, F2 is the most profitable and S2 played a favorable role in the distance between floral buds. The number of fruits is in favor of F1 and F2, S1 is the best. In terms of plant yield, F2 is the most favorable and $\mathrm{S} 2$ is the best. After that, F2 is the best recipe and F1 is the most economical. S1 and S2 did well in the development of the tomato plant by their proper physico-chemical properties. $\mathrm{S} 1$ is slightly better.
\end{abstract}

Keywords: soil-less culture, fertilizer, tomato, coconut fiber, grape marc, grow bag technique, stem length, number of nodes, distance between nodes, number of flower buds, distance between flower buds, number of fruits, yield

\section{Introduction}

Currently hydroponic cultivation is gaining popularity all over the world because of efficient resources management and quality food production. Soil based agriculture is now facing various challenges such as urbanization, natural disaster, climate change, indiscriminate use of chemicals and pesticides which is depleting the land fertility. Furthermore, the elevated labor cost of and land availability are leading to encourage hydroponic cultivation. Tomato cultivar is considered the second most important vegetable worldwide due to the high market demand, moreover, this crop is the most important greenhouse crop grown in aboveground systems (FAO, 2013). Furthermore, tomato yields are twice as high in aboveground cultivation as in the field (Urban and Urban, 2010). In the developing and third world countries like Lebanon, small-scale hydroponic crop growers have questions about which is the best cheapest substrate and fertilizer to use. To date, there is limited information concerning the physiological and yield responses of tomato plants and the reciprocal influence of substrate and different fertilizer recipes. As a substrate, the most commonly used granular materials in Mediterranean countries for bag culture are perlite, peat, coconut fiber, or a mixture. However, grape marc has not only special properties in ensuring rapid development of nursery plants (Ametqal, 1988) but has an economic advantage by replacing imported peat as a horticultural substrate. In this study, the responses of tomato crop exposed to different substrate and fertilizer has been investigated using morphological approaches. The objective of this work is to find a prototype for the hydroponic tomato crop with fertilizer modeling and substrate alternative, like grape marc, aiming to reduce the cost of production to the maximum and subsequently improve the farmer's income. 


\section{Method}

The experiment took place in 2017 at the "Centre de Recherche et de Formation Agricole" (CRFA) of the Faculty of Agriculture at the Lebanese University located in Ghazir in Keserwan Caza (Mount Lebanon), at an altitude of $550 \mathrm{~m}$.

\subsection{Experimental Design}

The experimental cultivars were planted in a $224 \mathrm{~m}^{2}(16 \mathrm{~m} \times 14 \mathrm{~m})$ Chapel greenhouse containing bags of tomato culture substrate, each containing 4 plants. The edge effect was eliminated. All work on culture was similar for all treatments. The tomato variety used in our experiment is the Yelliz variety. The 54 bags used in the experiment were divided into groups of 3 for each F1 fertilizer recipe, F2 and F3 and for each substrate S1, S2 and S3. The experimental setup used in our experiment was split plot design with three repetitions: block 1, block 2 and block 3. Each block contains the three fertilization recipes F1, F2 and F3 as major factors and the three substrates used $\mathrm{S} 1, \mathrm{~S} 2$ and $\mathrm{S} 3$ as sub factors (Figure 1).

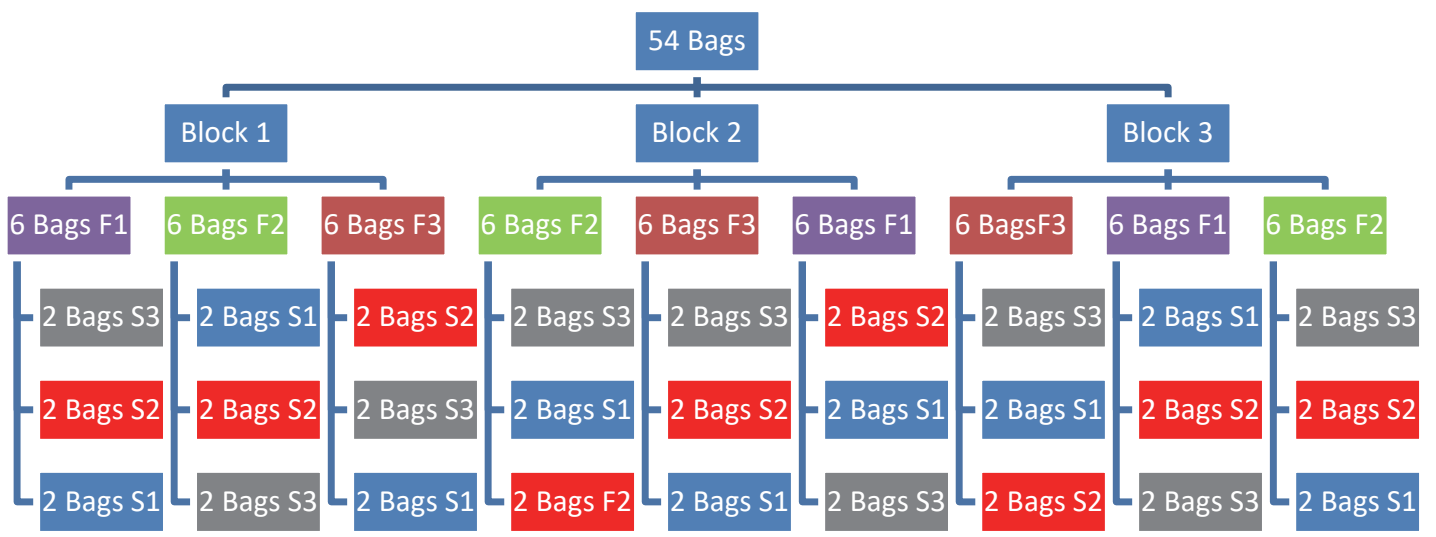

Figure 1. Experimental Design

\subsection{Substrate and Fertilization Recipe}

Three different substrate bags (23 liters each) were used; S1 (100\% coconut fiber), S2 (50\% coconut Fiber and $50 \%$ grape marc) and S3 (25\%coconut Fiber and 75\% grape marc). All substrates were analyzed at the IRAL Laboratories in Fanar (Table 1).

Table 1. Physico-chemical analysis of the substrates according to the IRAL.

\begin{tabular}{llll}
\hline Physicochemical parameters & Unit & Grape marc & Coconut fiber \\
\hline Moisture content & $\%$ & 32.17 & 11.32 \\
\hline Dry matter -DM- & $\%$ & 67.83 & 88.68 \\
\hline Ash & $\%$ & 16.69 & 5.55 \\
\hline pH water (1 :10) & $1: 10$ & 7.45 & 5.19 \\
\hline Electrical Conductivity (EC) $1: 10$ & $\mathrm{mS.cm}{ }^{-1}$ & 5.15 & 0.61 \\
\hline Organic material (combustion) (\%DM) & $\% \mathrm{DM}$ & 83.31 & 94.45 \\
\hline Carbon (combustion) (\%DM) & $\% \mathrm{DM}$ & 46.28 & 52.47 \\
\hline Nitrogen Kjeldahl (\%DM) & $\% \mathrm{DM}$ & 0.46 & 1 \\
\hline C/N & - & 100.61 & 53 \\
\hline P2O5 total (digestion) (\%DM) & $\% \mathrm{DM}$ & 0.39 & 0.29 \\
\hline Total K2O (digestion) (\%DM) & $\% \mathrm{DM}$ & 3.07 & 4.82 \\
\hline
\end{tabular}


Table 2. Components of the F1, F2 and F3 fertilization recipes during the three phases of the production cycle in ppm

\begin{tabular}{|c|c|c|c|c|c|c|c|c|c|}
\hline \multirow{2}{*}{$\begin{array}{l}\text { Components of the } \\
\text { various fertilization } \\
\text { recipes }\end{array}$} & \multicolumn{3}{|c|}{$\begin{array}{l}\text { Phase I } \\
0-6 \text { weeks }\end{array}$} & \multicolumn{3}{|c|}{$\begin{array}{l}\text { Phase II } \\
6-12 \text { weeks }\end{array}$} & \multicolumn{3}{|c|}{$\begin{array}{l}\text { Phase III } \\
12 \text { weeks and more }\end{array}$} \\
\hline & F1 & F2 & F3 & F1 & F2 & F3 & F1 & F2 & F3 \\
\hline Nitrogen $(\mathrm{N})$ & 237.50 & 224.00 & 200.00 & 376.18 & 189.00 & 198.00 & 376.18 & 189.00 & 281.00 \\
\hline Phosphorus (P) & 140.70 & 47.00 & 87.30 & 125.00 & 47.00 & 78.75 & 125.00 & 39.00 & 89.60 \\
\hline Potassium (K) & 216.60 & 281.00 & 165.30 & 434.00 & 351.00 & 327.30 & 434.00 & 341.00 & 340.50 \\
\hline Calcium $(\mathrm{Ca})$ & 57.00 & 212.00 & 0.00 & 171.00 & 190.00 & 190.00 & 171.00 & 170.00 & 171.00 \\
\hline Magnesium (Mg) & 39.72 & 65.00 & 0.84 & 75.85 & 60.00 & 1.40 & 75.85 & 48.00 & 1.68 \\
\hline $\operatorname{Iron}(\mathrm{Fe})$ & 12.53 & 2.00 & 3.40 & 13.95 & 2.00 & 4.60 & 13.95 & 2.00 & 5.40 \\
\hline Manganese (Mn) & 4.97 & 0.55 & 2.30 & 4.46 & 0.55 & 3.30 & 4.46 & 0.55 & 3.90 \\
\hline Zinc (Zn) & 1.02 & 0.33 & 2.90 & 5.84 & 0.33 & 4.30 & 5.84 & 0.33 & 5.10 \\
\hline Boron (B) & 2.44 & 0.28 & 1.10 & 2.20 & 0.28 & 1.62 & 2.20 & 0.28 & 1.92 \\
\hline Copper $(\mathrm{Cu})$ & 0.13 & 0.05 & 0.40 & 0.85 & 0.05 & 0.62 & 0.85 & 0.05 & 0.75 \\
\hline Molybdenum (Mo) & 0.11 & 0.05 & 0.07 & 0.10 & 0.05 & 0.07 & 0.10 & 0.05 & 0.08 \\
\hline
\end{tabular}

Three fertilization recipes were administered (Table 2); F1 (fertilizer recipe adopted by CRFA), F2 (fertilizer recipe adopted by Arizona University), F3 (traditional fertilizer used by the majority of Lebanese farmers-direct communication).

The grape marc was pre-sterilized using solarization. The fertilization of the tomatoes was applied via an irrigation venturi system with a dosatron. The flow of the drippers is $41 / \mathrm{H}$.

\subsection{Cost of Fertilization}

The cost of fertilization recipes used during the 3 production phases was calculated, and is presented in Table 3 .

Table 3. Cost of Fertilizer Recipes used during the production phases (\$).

\begin{tabular}{llll}
\hline Cost in $\$$ & $\begin{array}{l}\text { Phase I } \\
(0-6 \text { weeks })\end{array}$ & $\begin{array}{l}\text { Phase II } \\
(6-12 \text { weeks })\end{array}$ & $\begin{array}{l}\text { Phase III } \\
(12 \text { weeks and more })\end{array}$ \\
\hline F1 & 48.2 & 50.3 & 50.3 \\
F2 & 19.7 & 21.1 & 20.1 \\
F3 & 16.2 & 24.4 & 31.5 \\
\hline
\end{tabular}

\subsection{Studied Parameters}

Data were collected regularly throughout crop growth, and yield data were collected at harvest. The length of the stem, number and distance between the nodes and number and distance between flower buds were measured using a measuring tape manually for each plant. During harvesting, the fruits of each flower bud were weighed using a precision scale for each plant and each treatment.

\subsubsection{Ec and $p H$ Measurements}

During the entire experimental study, a daily measurement of the EC (entrance and exit) and $\mathrm{pH}$ (entrance and exit) were executed. Electrical conductivity (EC) was maintained between 1.83 and $2.77 \mathrm{~ms} / \mathrm{cm}$, and a target $\mathrm{pH}$ was maintained between 6.15 and 7.25. The optimal $\mathrm{pH}$ of most hydroponic cultures is between 5.8 and 6.3, whereas values between 5.0-5.5 and 6.5 - 7 do not cause problems for the majority of cultures (Adams, 2002). 


\subsection{Statistical Analysis}

The tables and figures were made on the EXCEL 2010 program while the statistical analyzes were processed with GLM (General Linear Model) using the Sigmastat program. The significant differences between the three types of fertilizer, the three different substrates and their interactions were analyzed with ANOVA two ways Repeated measures. Duncan test was used to indicate significantly different treatments.

\section{Results}

\subsection{Effects of Fertilization and Substrate on Different Parameters}

\subsubsection{Stem Length}

Concerning fertilization, the length of the stem with F2 treatment showed a slight non-significant superiority $(\mathrm{P}>0.05)$, during the $1^{\text {st }}$ and $3 \mathrm{rd}$ phases. This can be explained according to Hopkins (2003) by the amount of phosphorus raised in the F1 and F3 solutions which has the opposite effect as the nitrogen and therefore encourages a development of the root system. However during the 2nd phase, the length of the stem with F1 was slightly greater than the other two recipes. This can be explained by the increase in the amount of nitrogen in the fertilizer solution, in agreement with Hopkins (2003) who has proved that an excess of nitrogen stimulates exuberant growth of the aerial part, thus favoring an increase in the shoot/leaf ratio. This findings are similar to Saimbhi and Satpal (2003); Nawaz et al., 2012; Hozhbryan (2013). Concerning the substrate, the stem length during the production cycle are in favor of S1. This is due to the problems of water retention by the substrate that contains the grape marc. According to the analyzes conducted at IRAL (2017), grape marc shows a high water content compared to the coconut substrate and therefore its water retention is minimal (Birle et al., 2008). Those results agree with Sibomana et al. (2013) who confirmed that water deficit leads to a reduction in the length of the stem.

\subsubsection{Number of Nodes}

During the 1st phase, the number of nodes showed a slight non-significant superiority $(\mathrm{P}>0.05)$ for the F2 treatment. During the $2^{\text {nd }}$ and 3 rd phase, the number of nodes reported a significant difference $(P<0.05)$ with a superiority for F1 and F2 treatments. This can be explained by the fact that excess nitrogen increases the length of the stem, between nodes and decreases the number of nodes (Han, 2014). Dhiman and Raturi (2018) similarly reported that the number of nodes increases with a high rate of nitrogen and phosphate. The results of the number of nodes are in favor of F2, half the cost of fertilizer is sufficient for a good development of the tomato plant.

Substrates S1 and S3 exhibited a high number of nodes relative to substrate S2 with a priority for S1. This is due to the problems of water retention by the substrate that contains grape marc. According to IRAL (2017), water affects the growth of plants by acting on their physiological processes and their states.

\subsubsection{Node Distance}

During the different production phases, the distance between the nodes showed a slight non-significant superiority $(\mathrm{P}>0.05)$ for the F1 treatment. This can be explained by the amount of nitrogen and potass in the F1 recipe that causes an increase in the stem of the plant. Similarly, a high amount of potass causes a high distance between nodes, this is in agreement with Upendra et al., (2003) who showed that a decrease in potassium will lead to a small distance between nodes. However the use of F2 is more economical. Moreover the distance between nodes showed a roughly similar non-significant value $(\mathrm{P}>0.05)$ for the three substrate with a priority for the treatment $\mathrm{S} 1$. This can be explained by the high water requirement of the tomato plant. Water stress has an effect on plant growth (Lemay, 2006).

\subsubsection{Number of Flower Buds}

During the experiment, the number of flower buds showed a significant difference $(\mathrm{P}<0.05)$ in favor of treatments F1 and F2 which present maximum values with a superiority for F1. According to Kumar et al. (2013) and Balemi (2008), phosphorus helps flower initiation and formation. The F1 treatment was the best given its high NPK content, as proved by Shukla et al. (2009) and Haque et al.(2011), which reported that a high amount of fertilizer resulted in a superior number of flower buds. From the economic point of view, the results obtained deduce that the use of half the fertilization cost in F2 compared to F1 gave acceptable values. During the first two phases, the number of flower buds of the three substrates did not show a significant difference and subsequently they have no effect. However, the S1 substrate is slightly higher, this can be explained by its availability in water during production (IRAL, 2017). During the 3rd phase, the number of flower buds showed a significant difference $(P<0.05)$ in favor of S1 and S3. According to Roumani et al. (2012), the amount of water affects early flowering. On the other hand, the $\mathrm{S} 3$ substrate which contains a high percentage of grape marc has a higher total amount of $\mathrm{P}_{2} \mathrm{O}_{5}$ than the coconut substrate (IRAL, 2017). 


\subsubsection{Distance Between Flower Buds}

During the different phases of production, the distance between the flower buds showed a slight non-significant inferiority $(\mathrm{P}>0.05)$ for the $\mathrm{F} 3$ treatment. This can be explained by the amount of high fertilizer that affects the distance between the flower buds. According to Chandra et al. (2003) excess fertilizer increases the vegetative development of the plant. The results of the fertilizer effect on the distance between flower buds are in favor of F1 and F2. Economically F2 is the most profitable. During the different phases of production, the distance between the flower buds showed a significant difference $(\mathrm{P}<0.05)$ of the different treatments with a priority for $\mathrm{S} 1$. This can be explained by the high and continuous irrigation frequency that has been applied to minimize the effect of the water retention problem. Moreover, it has affected the aeration of root development in S1 which has a high water retention. According to Roumani et al. (2012) the amount of average water plays a positive role on the early flowering time and the flower bud. However the high amount of water can lead to a disorder of the root system.

\subsubsection{Yield of The Plant}

The F1 and F2 treatments showed similarity. This can be explained by the amount of fertilizer in the F1 and F2 recipes. According to Bhattarai et al. (2015) and Aminifard et al. (2010), maximum plant yield is found in the fertilizer recipe that has a high NPK level. At the end of the production cycle, no significant difference has been reported in the yield of the plant. The results of the effects of the variation in different fertilization recipes on the yield of the plant are economically in favor of F2. During the different phases of production, the yield of the plant showed a significant difference $(\mathrm{P}<0.05)$ with a maximum value for treatments $\mathrm{S} 1$ and $\mathrm{S} 2$. While it reported a significant inferiority for the $\mathrm{S} 3$ treatment. In conclusion, a high temperature during the summer and a good water retention by the substrate play a favorable role in the yield of the plant. Furthermore, high temperature causes a significant reduction in tomato production (Cornillon, 1987). According to Larbi (2006), the quality and the doses of applied composts directly affect yields. Decreases in yield can be observed with immature and high $\mathrm{C} / \mathrm{N}$ composts or with too high application rates. A C/N $>20$ ratio favors flowering however, a ration lower than 20 , inhibit flowering. There is a competition between vegetative growth and the development of reproductive organs. This is consistent with our analysis at IRAL (Table 4) which confirms that the $\mathrm{C} / \mathrm{N}$ ratio of grape marc is twice that of cocopeat. In addition, Badiane et al. (2012) showed that a water deficit leads to a decrease in yield. According to IRAL (2017), grape marc EC is high, and according to Xu et al. (1995) fruit production is also affected by substrate EC. The results of the yield of the plant are in favor of S2.

Table 4. Effects of fertilization and substrate on different parameters

\begin{tabular}{|c|c|c|c|c|c|c|}
\hline Treatment & $\mathrm{F} 1$ & $\mathrm{~F} 2$ & F3 & S1 & $\mathrm{S} 2$ & S3 \\
\hline \multicolumn{7}{|c|}{ Length of the stem $(\mathrm{cm})$} \\
\hline 1rst phase & $132.5 \pm 3.8^{\mathrm{a}}$ & $134.3 \pm 7.0^{\mathrm{a}}$ & $132.4 \pm 3.6^{\mathrm{a}}$ & $134.2 \pm 6.1^{\mathrm{a}}$ & $132.8 \pm 4.7^{\mathrm{a}}$ & $132.1 \pm 4.1^{\mathrm{a}}$ \\
\hline 2nd phase & $265.9 \pm 5.7^{\mathrm{a}}$ & $263.1 \pm 16.3^{\mathrm{a}}$ & $262.7 \pm 7.9^{\mathrm{a}}$ & $268.9 \pm 9.4^{\mathrm{a}}$ & $262.9 \pm 11.4^{\mathrm{a}}$ & $260.0 \pm 10.2^{\mathrm{a}}$ \\
\hline 3rd phase & $532.5 \pm 29.8^{\mathrm{a}}$ & $533.9 \pm 19.3^{\mathrm{a}}$ & $517.4 \pm 25.9^{\mathrm{a}}$ & $539.5+26.8^{\mathrm{a}}$ & $509.0+22.2^{\mathrm{b}}$ & $535.4+17.2^{\mathrm{ab}}$ \\
\hline \multicolumn{7}{|l|}{ Number of nodes } \\
\hline 1rst phase & $18.6 \pm 0.9^{\mathrm{a}}$ & $19.0 \pm 1.1^{\mathrm{a}}$ & $18.8 \pm 0.8^{\mathrm{a}}$ & $18.7 \pm 1.3^{\mathrm{a}}$ & $18.9 \pm 0.9^{\mathrm{a}}$ & $18.8 \pm 0.7^{\mathrm{a}}$ \\
\hline 2nd phase & $39.2 \pm 0.9^{\mathrm{a}}$ & $38.3 \pm 1.5^{\mathrm{ab}}$ & $37.4 \pm 0.9^{b}$ & $38.8 \pm 1.4^{\mathrm{a}}$ & $37.8 \pm 1.4^{\mathrm{a}}$ & $38.2 \pm 1.2^{\mathrm{a}}$ \\
\hline 3rd phase & $83.0 \pm 5.4^{\mathrm{a}}$ & $82.1 \pm 3.1^{\mathrm{a}}$ & $80.1 \pm 3.2^{\mathrm{a}}$ & $82.9 \pm 4.4^{\mathrm{a}}$ & $78.4 \pm 2.7^{b}$ & $83.9 \pm 2.8^{\mathrm{a}}$ \\
\hline \multicolumn{7}{|c|}{ Nodes distance $(\mathrm{cm})$} \\
\hline Production cycle & $7.4 \pm 0.3^{\mathrm{a}}$ & $7.1 \pm 0.4^{\mathrm{a}}$ & $7.2 \pm 0.4^{\mathrm{a}}$ & $7.2 \pm 0.4^{\mathrm{a}}$ & $7.2 \pm 0.3^{\mathrm{a}}$ & $7.1 \pm 0.3^{\mathrm{a}}$ \\
\hline \multicolumn{7}{|c|}{ Number of floral buds } \\
\hline 1rst phase & $5.1 \pm 0.2^{\mathrm{a}}$ & $5.0 \pm 0.3^{\mathrm{ab}}$ & $4.9 \pm 0.1^{\mathrm{b}}$ & $5.1 \pm 0.3^{\mathrm{a}}$ & $4.9 \pm 0.2^{\mathrm{a}}$ & $4.9 \pm 0.2^{\mathrm{a}}$ \\
\hline 2nd phase & $11.9 \pm 0.4^{\mathrm{a}}$ & $11.6 \pm 0.5^{\mathrm{ab}}$ & $11.3 \pm 0.4^{\mathrm{b}}$ & $11.8 \pm 0.5^{\mathrm{a}}$ & $11.4 \pm 0.5^{\mathrm{a}}$ & $11.6 \pm 0.4^{\mathrm{a}}$ \\
\hline 3rd phase & $26.0 \pm 1.8^{\mathrm{a}}$ & $25.7 \pm 1.0^{\mathrm{a}}$ & $25.0 \pm 1.0^{\mathrm{a}}$ & $26.0 \pm 1.5^{\mathrm{a}}$ & $24.5 \pm 0.9^{\mathrm{b}}$ & $26.3 \pm 0.9^{\mathrm{a}}$ \\
\hline \multicolumn{7}{|c|}{ Distance floral buds $(\mathrm{cm})$} \\
\hline Production cycle & $17.7 \pm 1.0^{\mathrm{a}}$ & $17.7 \pm 0.7^{\mathrm{a}}$ & $17.2 \pm 0.8^{\mathrm{a}}$ & $17.9 \pm 0.9^{\mathrm{a}}$ & $16.9 \pm 0.7^{b}$ & $17.7 \pm 0.6^{\mathrm{ab}}$ \\
\hline \multicolumn{7}{|l|}{ Number of fruits } \\
\hline 1rst phase & $20.7 \pm 1.6^{\mathrm{a}}$ & $20.7 \pm 1.2^{\mathrm{a}}$ & $20.5 \pm 1.4^{\mathrm{a}}$ & $20.2 \pm 1.3^{\mathrm{a}}$ & $21.1 \pm 1.9^{\mathrm{a}}$ & $20.6 \pm 0.9^{\mathrm{a}}$ \\
\hline 2nd phase & $71.8 \pm 3.1^{\mathrm{a}}$ & $70.2 \pm 6.5^{\mathrm{a}}$ & $68.8 \pm 3.3^{\mathrm{a}}$ & $72.5 \pm 5.0^{\mathrm{a}}$ & $70.1 \pm 5.0^{\mathrm{a}}$ & $68.1 \pm 3.0^{\mathrm{a}}$ \\
\hline 3rd phase & $166.0 \pm 10.6^{\mathrm{a}}$ & $168.7 \pm 14.4^{\mathrm{a}}$ & $163.8 \pm 10.0^{\mathrm{a}}$ & $171.6 \pm 13.7^{\mathrm{a}}$ & $159.4 \pm 8.8^{\mathrm{a}}$ & $167.5 \pm 9.1^{\mathrm{a}}$ \\
\hline \multicolumn{7}{|l|}{ Yield(kg/plt) } \\
\hline Production cycle & $5.13 \pm 0.65^{\mathrm{a}}$ & $5.18 \pm 0.53^{\mathrm{a}}$ & $4.9 \pm 0.66^{\mathrm{a}}$ & $5.0 \pm 0.64^{\mathrm{ab}}$ & $5.4 \pm 0.45^{\mathrm{a}}$ & $4.76 \pm 0.55^{\mathrm{b}}$ \\
\hline
\end{tabular}

a, b, within the same row, indicate significant differences at $P>0.05$. 
Table 5. Interaction between different fertilization recipes and substrates on all parameters

\begin{tabular}{|c|c|c|c|c|c|c|c|c|c|}
\hline Treatment & F1S1 & F1S2 & F1S3 & $\mathrm{F} 2 \mathrm{~S} 1$ & $\mathrm{~F} 2 \mathrm{~S} 2$ & $\mathrm{~F} 2 \mathrm{~S} 3$ & F3S1 & $\mathrm{F} 3 \mathrm{~S} 2$ & F3S3 \\
\hline \multicolumn{10}{|c|}{ Length of the stem $(\mathrm{cm})$} \\
\hline 1rst phase & $133.2 \pm 1.9^{\mathrm{a}}$ & $131.8 \pm 2.2^{\mathrm{a}}$ & $132.7 \pm 1.9^{\mathrm{a}}$ & $139.3 \pm 2.0^{\mathrm{a}}$ & $135.1 \pm 2.0^{\mathrm{a}}$ & $132.1 \pm 2.0^{\mathrm{a}}$ & $130.5 \pm 2.0^{\mathrm{a}}$ & $134.6 \pm 1.9^{\mathrm{a}}$ & $131.8 \pm 1.9^{\mathrm{a}}$ \\
\hline 2nd phase & $266.9 \pm 3.4^{\mathrm{a}}$ & $266.8 \pm 3.8^{\mathrm{a}}$ & $264.8 \pm 3.4^{\mathrm{a}}$ & $272.8 \pm 3.6^{\mathrm{a}}$ & $266.6 \pm 3.6^{\mathrm{a}}$ & $257.0 \pm 3.6^{\mathrm{a}}$ & $267.9 \pm 3.6^{\mathrm{a}}$ & $262.4 \pm 3.4^{\mathrm{a}}$ & $257.4 \pm 3.4^{\mathrm{a}}$ \\
\hline 3rd phase & $550.4 \pm 14.1^{\mathrm{a}}$ & $499.5 \pm 15.6^{\mathrm{a}}$ & $548.2 \pm 14.1^{\mathrm{a}}$ & $539.7 \pm 14.9^{\mathrm{a}}$ & $543.7 \pm 14.7^{\mathrm{a}}$ & $538.8 \pm 14.7^{\mathrm{a}}$ & $529.1 \pm 15.1^{\mathrm{a}}$ & $504.9 \pm 14.0^{\mathrm{a}}$ & $519.6 \pm 14.0^{\mathrm{a}}$ \\
\hline \multicolumn{10}{|l|}{ Number of nodes } \\
\hline 1rst phase & $18.4 \pm 1.3^{\mathrm{a}}$ & $18.1 \pm 0.5^{\mathrm{a}}$ & $19.1 \pm 0.7^{\mathrm{a}}$ & $19.2 \pm 1.6^{\mathrm{a}}$ & $19.2 \pm 1.0^{\mathrm{a}}$ & $18.6 \pm 0.6^{\mathrm{a}}$ & $18.3 \pm 1.1^{\mathrm{a}}$ & $19.2 \pm 0.5^{\mathrm{a}}$ & $18.7 \pm 0.7^{\mathrm{a}}$ \\
\hline 2nd phase & $39.3 \pm 1.6^{\mathrm{a}}$ & $39.1 \pm 0.8^{\mathrm{a}}$ & $39.1 \pm 0.7^{\mathrm{a}}$ & $39.1 \pm 1.9^{\mathrm{a}}$ & $37.7 \pm 1.4^{\mathrm{a}}$ & $38.1 \pm 1.5^{\mathrm{a}}$ & $38.2 \pm 0.8^{\mathrm{a}}$ & $36.6 \pm 0.4^{\mathrm{a}}$ & $37.4 \pm 0.7^{\mathrm{a}}$ \\
\hline 3rd phase & $85.4 \pm 5.3^{\mathrm{a}}$ & $77.7 \pm 4.1^{\mathrm{a}}$ & $85.8 \pm 2.9^{\mathrm{a}}$ & $81.8 \pm 3.7^{\mathrm{a}}$ & $80.1 \pm 1.4^{\mathrm{a}}$ & $84.4 \pm 3.0^{\mathrm{a}}$ & $81.4 \pm 4.6^{\mathrm{a}}$ & $77.4 \pm 1.8^{\mathrm{a}}$ & $81.5 \pm 0.4^{\mathrm{a}}$ \\
\hline \multicolumn{10}{|c|}{ Nodes distance $(\mathrm{cm})$} \\
\hline Production cycle & $7.4 \pm 0.2^{\mathrm{a}}$ & $7.4 \pm 0.4^{\mathrm{a}}$ & $7.3 \pm 0.4^{\mathrm{a}}$ & $7.0 \pm 0.4^{\mathrm{a}}$ & $7.2 \pm 0.4^{\mathrm{a}}$ & $7.1 \pm 0.3^{\mathrm{a}}$ & $7.0 \pm 0.5^{\mathrm{a}}$ & $7.3 \pm 0.4^{\mathrm{a}}$ & $7.3 \pm 0.5^{\mathrm{a}}$ \\
\hline \multicolumn{10}{|c|}{ Number of floral buds } \\
\hline 1rst phase & $5.2 \pm 0.2^{\mathrm{a}}$ & $5.1 \pm 0.1^{\mathrm{a}}$ & $5.0 \pm 0.2^{\mathrm{a}}$ & $5.0 \pm 0.3^{\mathrm{a}}$ & $4.9 \pm 0.3^{\mathrm{a}}$ & $4.9 \pm 0.2^{\mathrm{a}}$ & $4.9 \pm 0.2^{\mathrm{a}}$ & $4.8 \pm 0.1^{\mathrm{a}}$ & $4.9 \pm 0.1^{\mathrm{a}}$ \\
\hline 2nd phase & $11.9 \pm 0.6^{\mathrm{a}}$ & $11.8 \pm 0.5^{\mathrm{a}}$ & $11.9 \pm 0.3^{\mathrm{a}}$ & $11.9 \pm 0.6^{\mathrm{a}}$ & $11.5 \pm 0.5^{\mathrm{a}}$ & $11.5 \pm 0.3^{\mathrm{a}}$ & $11.5 \pm 0.4^{\mathrm{a}}$ & $11.1 \pm 0.3^{\mathrm{a}}$ & $11.3 \pm 0.4^{\mathrm{a}}$ \\
\hline 3rd phase & $26.8 \pm 1.7^{\mathrm{a}}$ & $24.2 \pm 1.4^{\mathrm{a}}$ & $26.8 \pm 0.9^{\mathrm{a}}$ & $25.6 \pm 1.2^{\mathrm{a}}$ & $25.1 \pm 0.4^{\mathrm{a}}$ & $26.5 \pm 1.0^{\mathrm{a}}$ & $25.5 \pm 1.5^{\mathrm{a}}$ & $24.2 \pm 0.6^{\mathrm{a}}$ & $25.4 \pm 0.1^{\mathrm{a}}$ \\
\hline \multicolumn{10}{|c|}{ Distance floral buds $(\mathrm{cm})$} \\
\hline Production cycle & $18.3 \pm 0.7^{\mathrm{a}}$ & $16.6 \pm 0.8^{\mathrm{a}}$ & $18.2 \pm 0.4^{\mathrm{a}}$ & $17.9 \pm 1.0^{\mathrm{a}}$ & $17.4 \pm 0.8^{\mathrm{a}}$ & $17.8 \pm 0.4^{\mathrm{a}}$ & $17.5 \pm 1.2^{\mathrm{a}}$ & $16.8 \pm 0.6^{\mathrm{a}}$ & $17.2 \pm 0.7^{\mathrm{a}}$ \\
\hline \multicolumn{10}{|l|}{ Number of fruits } \\
\hline 1rst phase & $20.2 \pm 1.3^{\mathrm{a}}$ & $21.8 \pm 2.3^{\mathrm{a}}$ & $20.2 \pm 0.8^{\mathrm{a}}$ & $19.9 \pm 2.0^{\mathrm{a}}$ & $21.0 \pm 0.7^{\mathrm{a}}$ & $21.1 \pm 0.8^{\mathrm{a}}$ & $20.4 \pm 0.7^{\mathrm{a}}$ & $20.4 \pm 2.6^{\mathrm{a}}$ & $20.6 \pm 1.0^{\mathrm{a}}$ \\
\hline 2nd phase & $72.2 \pm 5.2^{\mathrm{a}}$ & $73.3 \pm 0.8^{\mathrm{a}}$ & $70.0 \pm 0.8^{\mathrm{a}}$ & $72.9 \pm 8.1^{\mathrm{a}}$ & $69.0 \pm 8.4^{\mathrm{a}}$ & $68.7 \pm 4.4^{\mathrm{a}}$ & $72.5 \pm 2.2^{\mathrm{a}}$ & $68.0 \pm 2.1^{\mathrm{a}}$ & $69.0 \pm 4.1^{\mathrm{a}}$ \\
\hline 3rd phase & $174.1 \pm 9.6^{\mathrm{a}}$ & $156.3 \pm 6.3^{\mathrm{a}}$ & $167.4 \pm 8.7^{\mathrm{a}}$ & $172.3 \pm 23.4^{\mathrm{a}}$ & $162.9 \pm 13.7^{\mathrm{a}}$ & $171.0 \pm 4.3^{\mathrm{a}}$ & $168.3 \pm 9.3^{\mathrm{a}}$ & $159.0 \pm 6.8^{\mathrm{a}}$ & $164.2 \pm 14.3^{\mathrm{a}}$ \\
\hline \multicolumn{10}{|l|}{ Yield(kg/plt) } \\
\hline Production cycle & $5.5 \pm 0.48^{\mathrm{a}}$ & $5.2 \pm 0.58^{\mathrm{a}}$ & $4.6 \pm 0.69^{\mathrm{a}}$ & $4.6 \pm 0.22^{\mathrm{a}}$ & $5.6 \pm 0.48^{\mathrm{a}}$ & $5.2 \pm 0.31^{\mathrm{a}}$ & $4.8 \pm 0.85^{\mathrm{a}}$ & $5.4 \pm 0.36^{\mathrm{a}}$ & $4.4 \pm 0.31^{\mathrm{a}}$ \\
\hline
\end{tabular}

a, b, within the same row, indicate significant differences at $P>0.05$.

\subsection{Interaction between Different Fertilization Recipes and Substrates on All Parameters}

\subsubsection{The Stem Length}

During the 1st phase, the length of the stem in the F2S1 treatment presented the maximum value of the length with a value of $139.3 \pm 2.0$. While it showed a slight non-significant inferiority $(\mathrm{P}>0.05)$ for the other treatments. During the 2nd phase, the maximum stem length is presented in the F2S1 treatment with a value of $272.8 \pm 3.6$. While it showed a slight non-significant superiority $(\mathrm{P}>0.05)$ for the other treatments. During the 3rd phase, the length of the stem in the F1S1 treatment was superior to other treatments which showed a slight insignificant inferiority $(\mathrm{P}>0.05)$. This can be explained by the amount of fertilizer and the importance of water retention for the development of the plant. The results of stem length during the three phases of production are in favor of F2S1.

\subsubsection{The Number of Nodes}

During the 1st phase, the number of nodes in the F2S1 processing presented the maximum value of the number of nodes with a value of $19.2 \pm 1.6$. While it showed a slight non-significant inferiority $(\mathrm{P}>0.05)$ for the other treatments. During the 2nd phase, the maximum number of nodes is presented in the F1S1 processing with a value of $39.3 \pm 1.6$. While it showed a slight non-significant superiority $(\mathrm{P}>0.05)$ for the other treatments. During the 3 rd phase, the number of nodes in the F1S1 treatment showed a superiority compared to the other treatments which presented a slight insignificant inferiority $(\mathrm{P}>0.05)$. Ewulo et al. 2015 proved our results and showed that a high nitrogen content stimulates exuberant growth of the vegetative part. According to Kramer (1983) water affects the growth of plants by acting on the physiological process and the state of the plants. Similarly, Lemay (2006) stated that plant growth is affected by its water status. The results of the number of nodes during the three phases of production are in favor of F2S1.

\subsubsection{The Distance Between Nodes}

During the different production phases, the distance between nodes did not show a significant difference between the different treatments. There is no interaction between fertilizers and substrates on the distance between nodes.

\subsubsection{The Number of Floral Buds}

Throughout the entire production cycle, the number of floral buds was not affected by all the interactions between the different fertilization treatments and the different substrates used. During the first phase, the two interactions 
F1S1 and F2S1 presented maximum values with a value of $5.2 \pm 0.2$ and $5.0 \pm 0.3$ respectively. During the 2nd phase, the maximum number of buds is presented in both F1S1 and F2S1 interactions with values of $11.9 \pm 0.6$. During the 3rd phase, the number of flower buds in the F1S1 interaction showed a superiority with $26.8 \pm 1.7$ compared with other interactions that showed a slight inferiority that was not significant $(\mathrm{P}>0.05)$.It can be concluded that fertilizers F1 and F2 play a major role in the number of floral buds and substrates S1 and S3 have a positive effect by their physicochemical properties, the 1 st by its high water retention and the 2 nd by its high percentage in $\mathrm{P}_{2} \mathrm{O}_{5}$.

\subsubsection{The Distance Between Flower Buds}

During the different phases of production, the interaction between the different fertilization recipes and the different substrates did not show a significant difference in the distance between the floral buds.

\subsubsection{The Number of Fruits}

During the different phases of production, the interaction between the different fertilization recipes and the different substrates did not show a significant difference in the number of fruits. A non-significant trend for F1S1 and F2S1 treatments can be explained by a high NPK level and a high water retention capacity that plays a major role in fruit formation (Chandra et al., 2003).

\subsubsection{The Yield of the Plant}

During the different phases of production, the interaction between the different fertilization recipes and the different substrates did not show a significant difference in the yield of the plant. But there is a trend for F2S2 treatment that shows the maximum value. This can be explained from previous analyzes by the high amount of fertilizer in $\mathrm{F} 2$ and a low $\mathrm{C} / \mathrm{N}$ ratio with high water retention capacity (Larbi, 2006).

\section{Conclusion}

According to our study, the different fertilization recipes and the different substrates used play a major role in the development of the tomato plant. The results of stem length and number of nodes during the three phases of production are in favor of F2 and $\mathrm{S} 1$ and good interaction is reported at F2S1. However, concerning the distance between nodes, the fertilization recipe F1 is the best, whereas the use of F2 is more economical. Substrate S1 showed superiority over F2. The different substrates and their interaction with the fertilization recipes did not show an effect on the distance between nodes. Moreover, the number of flower buds is positively affected by F1 and F2 fertilization recipes and S1 and S3 substrates. On the other hand, no interaction between the different fertilization recipes and the different substrates has been reported. Regarding the distance between flower buds, fertilization recipes F1 and F2 are the best. Economically F2 is the most profitable. The substrate S2 played a favorable role and the interaction between the different fertilization recipes and the different substrates is negligible. Furthermore, the number of fruits during the three phases of production is in favor of F1 and F2, the substrate S1 is the best. The interaction between the different fertilization recipes and the different substrates has no effect on the number of fruits. Finally, the fertilization recipe $\mathrm{F} 2$ is the most favorable and the substrate $\mathrm{S} 2$ is the best for the yield results. On the other hand, the interaction between the various fertilization recipes and the different substrates has no effect on the yield of the plant. In sum, it can be concluded that the fertilization recipe F2 is the best while F1 is the most economical. The F2 fertilization recipe represents half the cost of the F1 fertilization recipe and allows a good development of the tomato plant. Substrates S1 and S2 have succeeded in developing the tomato plant by their suitable physicochemical properties. The substrate $\mathrm{S} 1$ is slightly better. The interaction between the different fertilization recipes and the different substrates is almost negligible, a trend is in favor of F2S1. Thus, one can recommend to Lebanese farmers an F2 fertilization recipe suitable for growing above-ground tomato and an alternative of S2 substrate (50\% coconut fiber and 50\% grape marc) less expensive. In perspective, we recommend and plan to continue further work on the effect of grape marc after composting and study the variation of fertilization and irrigation rates during the production cycle.

\section{References}

Adams, P. (2002). Nutritional Control in Hydroponics. In Hydroponic Production of Vegetables and Ornamentals. Embryo Publications, Athens Greece, 211-261.

Ametqal, H. (1988). Use of grapes skins as a horticultural growing media, FAO.

Aminifard, M. H., Aroiee, H., Fatemi, H., Ameri, A., \& Karimpour, S. (2010). Responses of eggplant (Solanum melongena L.) to different rates of nitrogen under field conditions. Journal of Central European Agriculture, 11(4), 453-458. https://doi.org/10.1590/1807-1929/agriambi.v21n1p21-26

Badiane, A., Ndeye, Y., Fatou, G., Saliou, F., Ibrahima, N., \& Dominique, M. (2012). Effects of different inputs of organic matter on the response of plant production to a soil water stress in Sahelian region. Disponible sur 
http://dx.doi.org/10.4236/ns.2012.41212, 2012

Balemi, T. (2008). Response of tomato cultivars differing in growth habit to nitrogen and phosphorus fertilizers and spacing on vertisol in Ethiopia. Acta Agriculturae Slovenica, 91(1), 103-119. Journal of Agriculture Science, 24(1) 55-59.

Bhattarai, P., Kaushik, R. A., Ameta, K. D., Jain, H. K., Kaushik, M. K., \& Sharma, F. L. (2015). Effect of plant geometry and fertigation on growth and yield of cherry tomato (Solanum lycopersicon var. cerasiforme) under zero energy polyhouse conditions. Indian Journal of Horticulture, 72, 297-301. https://doi.org/10.5958/0974-0112.2015.00057.2

Birle, E., Heyer, D., \& Vogt, N. (2008). Influence of the initial water content and dry density on the soil-water retention curve and the shrinkage behavior of a compacted clay. Acta Geotechnica, 3, 191-200.

Chandra, P., Singh, A. K., Behera, T. K., \& Srivastava, R. (2003). Influence of graded levels of nitrogen, phosphorus and potassium on the yield and quality of tomato (Lycopersicon esculentum) hybrids grown in a polyhosue. Indian J. Agric. Sci., 73(9), 497-499.

Cornillon, P. (1987). Les exigences des espèces, In Culture hors-sol, INRA, Paris. P 22.

Dhiman, S., \& Raturi, H. (2018). Effect of Nitrogen and Phosphorus on tomato (solanum lycopersicum L.) grown under polyhouse condition: 25-28.

Ewulo, B. S., Sanni, K. O., \& Adesina, J. M. (2015). Response of tomato (Lycopersicum esculentum Mill.) to different levels of nitrogen and phosphorus fertilizer in South Western Nigeria. International Journal of Applied and Pure Science and Agriculture, 1(10), 13-20.

FAO. (2013). Résultats de la production de tomate mondiales, FAO stat.

Han, P., Violette, A., \& Desneux, N. (2014). Nitrogen and water availability to tomato plants triggers bottom-up effects on the leafminer Tuta absoluta. Nature Research.

Haque, M. E., Paul, A. K., \& Sarker, J. R. (2011). Effect of nitrogen and boron on the growth and yield of tomato (Lycopersicon esculentum Mill.). International Journal of Bio-resource and Stress Management, 2(3), 277282.

Hopkins, G. (2003). Physiologie Vegetale. De Boeck University. P:67-70.

Hozhbryan, M. (2013). Effect of different levels of urea on the growth and yield of tomato. Journal of Novel Applied Sciences 2(S3): 1031-1035. (C2013 JNAS Journal-2013-2-S3/1031-1035 ISSN 2322-5149 (C2013 JNAS Internet 6: Sunco, Ltd., and University of Arizona, Controlled Environment Agriculture Center, consultée le 10 mai 2017. Retrieved from http://tinyurl.com/ljlj785/

IRAL. (2017). Analyse physico-chimique des substrats.

Kramer, P. J. (1983). Water Relations of Plants. Science direct: 235-261

Kumar, M., Meena, M. L., Kumar, S., Maji, S., \& Kumar, D. (2013). Effect of nitrogen, phosphorus and potassium fertilizers on the growth, yield and quality of tomato var. Azad T-6. The Asian Journal of Horticulture, 8(2), 616- 619.

Larbi, M. (2006). Influence de la qualité des composts et de leurs extraits sur la protection des plantes contre les maladies fongiques. Thèse de doctorant. Université de Neuchâtel, Faculté des Sciences, p.161

Lemay, I. (2006). Régies d'irrigation et rendement de la tomate de serre en mélange sciure-tourbe. P.6.

Nawaz, H., Zubair, M., \& Derawadan, H. (2012). Interactive effects of nitrogen, phosphorus and zinc on growth and yield of Tomato (Solanum lycopersicum). African Journal of Agricultural Research, 7(26), 3792-3769. https://doi.org/10.5897/AJAR12.1027

Roumani, M., Kechebar, M. S. A., Tabet, S., Djoudi, A. M., Barbari, F., Salem, A., \& Ziad, M. S. (2012). Influence du type d'irrigation sur les paramètres de production de la culture de la tomate bio sous abri dans la plain d'el outaya. Journal algériens des régions arides No.9/10/11:66-70.

Saimbhi, M. S., \& Satpal, S. (2003). Effect of varying levels of nitrogen and phosphorus on earliness and yield of brinjal hybrids. Journal of Research of Crops, 4, 217-222.

Shukla, Y. R., Thakur, A. K., \& Joshi, A. (2009). Effect of inorganic and bio-fertilizer on yield and horticultural traits in tomato. Indian Journal of Horticulture, 66(2), 285-287.

Sibomana, I. C., Aguyoh, J. N., \& Opiyo, A. M. (2013). Water stress affects growth and yield of container grown 
tomato (Lycopersicon esculentum Mill) plants. Global Journal of Bio-Science and Biotechnology, 2(4), 461466. science and nature.org/GJBB_Vol2(4)2013/GJBB- V2(4) 2013-1

Upendra, M. S., Ramdane, D., \& Bharat, S. (2003). Mineral nutrition of tomato. Agricultural Research Station, Fort Valley State University, Fort Valley, Georgia 31088, USA. Research Gate.

Urban, L., \& Urban, I. (2010). La production sous serre, tomate 2: l'irrigation fertilisante en culture hors sol, Paris. Chapitre, 1, 2-40.

Xu, H. L., Gauthier, L., \& Gosselin, A. (1995). Effects of fertigation management on growth and photosynthesis of tomato plant grown in peat, rockwool and NFT. Scientia Hort, 63, 11-20. https://doi.org/10.1016/03044238(95)00791-Q

\section{Copyrights}

Copyright for this article is retained by the author(s), with first publication rights granted to the journal.

This is an open-access article distributed under the terms and conditions of the Creative Commons Attribution license (http://creativecommons.org/licenses/by/4.0/). 